\title{
Analise dos Parâmetros Físicos: Sólidos Totais, Sólidos Sedimentáveis, Sólidos Totais Dissolvidos e Sólidos Suspensos nas Águas do Vale do Açu
}

\author{
Ronison Inocencio Nunes* (Graduando em Química no Instituto Federal de Educação, Ciência e \\ Tecnologia do Rio Grande do Norte - IFRN) \\ Wadna Wanaganne de Souza (Graduando em Química no Instituto Federal de Educação, \\ Ciência e Tecnologia do Rio Grande do Norte - IFRN) \\ Paulo Ricardo Felipe dos Santos (Graduando em Química no Instituto Federal de Educação, \\ Ciência e Tecnologia do Rio Grande do Norte - IFRN) \\ J oyce Bezerra de Oliveira (Graduando em Química no Instituto Federal de Educação, Ciência e \\ Tecnologia do Rio Grande do Norte - IFRN) \\ Judiclênia Macedo Santana (Graduando em Química no Instituto Federal de Educação, Ciência e \\ Tecnologia do Rio Grande do Norte - IFRN) \\ Ozanira Soares Maciel (Técnica de Laboratório no Instituto Federal de Educação, Ciência e \\ Tecnologia do Rio Grande do Norte - IFRN) \\ Diogo Pereira Bezerra (Prof. Do Curso de Química no Instituto Federal de Educação, Ciência e \\ Tecnologia do Rio Grande do Norte - IFRN) \\ *E-mail: Ronison.nunes@hotmail.com
}

\section{RESUMO}

Sabe-se que a atual conjuntura de seca na região Nordeste já prevalece a pouco mais de quatro anos. E no Estado do Rio Grande do Norte a situação não diferencia dos demais. Atualmente o maior reservatório que está posicionado numa das importantes reservas hídricas do RN está operando muito a baixo, de sua capacidade total cerca de $75 \%$ a menos, ou 25,5\% do total, (DNOCS) a Barragem Armando Ribeiro Gonçalves além de abastecer mais de 30 cidades do interior, também alimenta grandes empreendimentos de empresas multinacionais que se estabeleceram na região para a produção de frutas, gerando emprego e renda as populações do vale do Açu. Além disso, vale ressaltar que é com águas da Barragem, que o Rio Piranhas Açu é perpetuado banhando diversas cidades até sua foz que vai até o litoral Norte, nos limites da cidade salineira de Macau. Por vários fatores a água torna-se para todos os seres vivos, um bem precioso, se não o mais importante à sobrevivência de todos, mas o ser humano sem medir consequências acaba degradando o que a natureza nós oferece. Segundo a ONU cerca de $80 \%$ da população mundial vive em áreas com altos níveis de ameaça à segurança da água. As ameaças mais graves afetam 3,4 bilhões de pessoas, quase todas nos países em desenvolvimento. No Caso do Brasil apesar da grande quantidade de água encontrada nos rios amazônicos, nada se pode fazer, pois o país consiste numa ampla diversidade de biomas, e habitats cada um com particularidades diferenciadas. A partir dessas considerações o Programa Águas Potiguares desenvolvido em quatro campis do IFRN, traz a seguinte proposição de monitorar a qualidade da água nas regiões entorno de cada instituto, além de fazer a conscientização do uso racional da água. Para isso faz jus aos regimentos da resolução 357/2005 do CONAMA (Conselho Nacional do Meio Ambiente), analisando cerca de 24 parâmetros físico-químicos. Assim a presente proposta de estudo tem por Objetivo, analisar os parâmetros físicos: Sólidos Totais, Sólidos Sedimentáveis sólidos totais dissolvidos e Sólidos Suspensos. E analisar os resultados comparando suas correlações existentes, nas águas da Barragem Armando Ribeiro Gonçalves, Rio Açu e Açude de Pataxó.

PALAVRAS-CHAVE: Águas Potiguares, Vale do Açu. 


\section{I NTRODUÇÃO}

A Água é um bem natural, que além de servir ao consumo humano, faz o desenvolvimento de diversas indústrias que necessitam dela, para poder movimentar grandes e pequenos empreendedores. A Produção de energia, por exemplo, que no Brasil é concedida pouco mais de 95\% da geração pelas águas, de grandes Rios do País, para agricultura são gastos cerca de $70 \%$ de toda água para a manutenção da irrigação.

$\mathrm{Na}$ Microrregião do vale do Açu, grandes empresas multinacionais, empreenderam nas terras férteis do vale, pois segundo (SILVA, 2007). É notório o potencial para a exploração da agricultura irrigada no Vale do Açu, considerando os recursos naturais disponíveis na região, como: solo de boa qualidade, clima favorável ao desenvolvimento de cultivos agrícolas, como também recursos hídricos disponíveis da barragem Engenheiro Armando Ribeiro Gonçalves. Sendo de grande importância para a economia do estado e da região, que teve expressivo crescimento entre as décadas de 80 até os dias atuais, mas com o longo período de estiagem o cenário é outro, onde não há água não tem como produzir, e com os reservatórios secando a produtividade vem caindo gradualmente. Segundo a ONU cerca de $80 \%$ da população mundial vive em áreas com altos níveis de ameaça à segurança da água.

E como determina a lei o 9.433 , de oito de janeiro de 1997, no Art 1 A Política Nacional de Recursos Hídricos baseia-se nos seguintes fundamentos: I - a água é um bem de domínio público; II - a água é um recurso natural limitado, dotado de valor econômico; III - em situações de escassez, o uso prioritário dos recursos hídricos é o consumo humano e a dessedentação de animais; (BRASIL, 1997). Sendo assim é sabido que as águas devem atender primeiramente as necessidades de consumo humano. Porém o homem em sua irracionalidade trata desses recursos de forma inadequada causando degradação, e danos irreparáveis ao meio ambiente aquático e vegetal.

A Barragem Armando Ribeiro Gonçalves é o maior reservatório de agua doce do Estado foi construída pelo DNOCS, com capacidade de 2,4 bilhões de metros cúbicos. 0 Rio Açu que é perenizado pela barragem e corta diversas cidades até a foz, no atlântico Norte. O Açude de Pataxó barra o rio Pataxó, afluente do rio Açu (ou Piranhas), e localizase no município de I panguaçu, estado do Rio Grande do Norte, com sua capacidade de 24.500.000 $\mathrm{m}^{3}$ de água. O principal objetivo do açude é a regularização do rio Pataxó, propiciando a irrigação da várzea. Além disso, o sistema Pataxó - Lagoa da Ponta Grande regulariza o fluxo de água para a lagoa, permitindo um melhor desenvolvimento da agricultura naquela região. Logo a influência da agricultura é o efeito antrópico, mais 
presente nessa região causado principalmente pelo uso de agrotóxicos, e carreio de sólidos nas águas que correspondem a toda matéria que permanece como resíduo, após evaporação, secagem ou calcinação da amostra a uma temperatura pré-estabelecida durante um tempo fixado. E são levados para a margem do rio, e açude através das chuvas. Que pode provocar além de assoreamento, uma grande concentração de partículas sedimentadas nos corpos hídricos.

Sendo assim o Programa Águas Potiguares desenvolvidos pelo IFRN, traz a seguinte proposição de monitorar a qualidade da água nas regiões entorno de quatro institutos, além de fazer a conscientização do uso racional da água. Logo o presente estudo tem por finalidade, analisar os parâmetros físicos: Sólidos Totais, Sólidos Sedimentáveis sólidos totais dissolvidos e Sólidos Suspensos, e determinar os níveis de qualidade determinados pelo CONAMA, além de correlacionar os resultados obtidos entre as amostras.

\section{METODOLOGIA}

\subsection{Coleta}

As coletas das alíquotas foram realizadas em três mananciais sendo eles barragem Engenheiro Armando Ribeiro Gonçalves, rio Piranhas Açu e Açude de Pataxó. Para os dias 11/08 a 22/09 seguido da estação do ano caracterizada pela transição entre Inverno e Primavera de acordo com as datas analisadas. Em que se recolheu as amostras sempre nas primeiras horas do dia, todo o material foi adequadamente colhido em recipientes de polietileno exaustivamente lavados e enxaguados previamente com água destilada. As águas tiveram três pontos de coleta dissemelhante dos mananciais sendo cada uma recolhida com a profundidade de 20 centímetros da superfície. Logo em seguida conduzidas ao o Laboratório de química no Instituto Federal de Educação, Ciência e Tecnologia do Rio Grande do Norte - IFRN/Campus I panguaçu, onde foram realizadas as análises tanto físicas, quanto químicas.

\subsection{Sólidos totais}

Lavou-se previamente a cápsula de porcelana como maneira de retirar qualquer impureza para não afetar os resultados. Aqueceu por uma hora em uma estufa a uma temperatura variando entre $103-105^{\circ} \mathrm{C}$. Ao retirar, resfriar até a temperatura ambiente 
em um dessecador. Após atingir a temperatura, pesa-se a cápsula e anota-se o valor. Homogeneíza-se bem a amostra tendo o cuidado de eliminar previamente os possíveis interferentes. Medir $100 \mathrm{~mL}$ da amostra, e transferi-la para a cápsula. Novamente fazse o processo de Evaporação desta vez utilizando a amostra na estufa entre $103-105^{\circ} \mathrm{C}$ por uma hora. Após a evaporação, levar a cápsula para o dessecador e deixa-la esfriar. Em seguida pesa-se novamente a cápsula.

\subsection{Sólidos Totais Dissolvidos}

Processo Experimental dos Sólidos Totais Dissolvidos torna-se semelhante ao anterior em que se Lava previamente a cápsula de porcelana. Aquece por uma hora em uma estufa a $105^{\circ} \mathrm{C}$. Ao retirar, resfriar até a temperatura ambiente em um dessecador. Após atingir a temperatura, pesa-se a cápsula e anota-se o valor. Homogeneíza-se bem a amostra tendo o cuidado de eliminar previamente os possíveis interferentes. Medir 100 $\mathrm{mL}$ da amostra, e filtra o volume medido da amostra em sistema de filtração á vácuo, mediante o filtro de fibra de vidro. Transferi o filtrado para a cápsula previamente seca. Evapora-se a amostra na estufa entre $103-105{ }^{\circ} \mathrm{C}$ por uma hora. Após a evaporação, levar a cápsula para o dessecador e deixa-la esfriar. Em seguida pesa-se novamente a cápsula. Todo esse processo consiste na medição fazendo a diferença do que se obtinha antes e depois, da filtração e evaporação da amostra.

\subsection{Sólidos Suspensos}

Processo experimental de sólidos suspensos se dá por meio de filtração em bomba a vácuo, utiliza-se $1000 \mathrm{ml}$ de amostra, coletado de cada corpo hídrico. Sendo montado um sistema que consiste em, um kitassato; filtro de fibra vidro; filtro de papel; garras metálicas; e bomba a vácuo. Como procedimento lava-se o filtro de papel por três vezes com $20 \mathrm{ml}$ de água destilada, em seguida elimina-se o filtrado da lavagem. Após esse primeiro passo pode-se dar sequencia na filtração da alíquota. Na segunda etapa leva-se o papel filtro á estufa para secagem em cerca de $103 c^{\circ}$ a $105 c^{\circ}$, por uma hora em capsula de porcelana. Terceiro passo é retirar o material já seco, e aguardar ficar em temperatura ambiente. Por ultimo se faz a pesagem do material seco junto com á capsula de porcelana. Por fim, é feito o cálculo. 


$$
\frac{m g}{L s S}=\left(\frac{B-A \cdot 1000}{V \cdot a}\right)
$$

(1) Calculo utilizado na medição de sólidos suspensos.

Onde: A: peso da capsula em mg;

B: peso da capsula com resíduo após secagem em mg;

V.a: volume da amostra em L.

\subsection{Sólidos sedimentáveis}

Os sólidos sedimentáveis das águas superficiais e salinas, bem como de resíduos domésticos e industriais, podem ser determinados e expressos em função de um volume $(\mathrm{ml} / \mathrm{L})$ ou de um peso $(\mathrm{ml} / \mathrm{L})$. A designação de sólidos sedimentáveis é aplicada a sólidos em suspensão na água que decantam em certas condições, devido a ação da gravidade. Somente os sólidos em suspensão de maiores sedimentações, que tem um peso especifico maior do que da água, decantarão. A acumulação dos sólidos sedimentáveis formam o lodo.

\section{RESULTADOS E DISCUSSÕES}

Foram feitas quatro analises, em que se deram semanalmente na qual o ensaio se mostrou bastante produtivo e satisfatório, pois através desse estudo foi possível mensurar a qualidade da água e relacionar as possíveis causas, para o bom ou ruim resultado na potabilidade da água. De acordo com os dados obtidos através das análises nota-se a partir das tabelas 1 e 2 que os valores para sólidos totais dissolvidos, sólidos totais e sólidos suspensos ultrapassam os valores permitidos pela resolução 357/2005 do CONAMA que preconiza, valor máximo permitido de $500 \mathrm{mg} / \mathrm{L}$ de sólidos dissolvidos totais para águas para consumo humano, classe 1. Isso se deve positivamente ao estado atual dos mananciais em exceção ao açude de pataxó que obteve sangria neste ano, já os demais sofrem com a seca, e as atividades antrópicas que causam grande impacto ambiental e percebido pelas análises. Segundo o IGARN (2007). A disposição dos resíduos sólidos urbanos próximos ao rio torna-se um grande perigo para a saúde que além de contaminar suas águas, favorece a proliferação de vetores de doenças (ratos, escorpiões, baratas, etc.). Ao em torno do leito do rio, se tem uma grande quantidade 
de criação de animais, causando assim poluição proveniente de excremento provido dos currais, em que os principais impactos negativos identificados na região denotam da agricultura irrigada, as fazendas de banana/ manga/mamão, são inclusive um dos fatores responsáveis.

Tabela 1 - Análise para sólidos suspensos.

\begin{tabular}{c|cc|}
$\begin{array}{c}\text { Local da coleta entre os dia 10/09 a 15/09 } \\
\text { Barragem Eng. A. R. G }\end{array}$ & $\begin{array}{l}\text { Sólidos } \\
\text { Suspensos } \\
\text { (mg/L) }\end{array}$ & $\begin{array}{l}\text { Sólidos } \\
\text { Suspensos } \\
\text { (mg/L) }\end{array}$ \\
\hline Rio Piranhas - Açu & 1140 & 1650 \\
Açude Pataxó & 590 & 1000 \\
& 710 & 700
\end{tabular}

Tabela 2 - Análise para sólidos Totais e Dissolvidos.

\begin{tabular}{|c|c|c|c|c|}
\hline \multicolumn{5}{|c|}{ Rio Piranhas-Açu } \\
\hline Parâmetro & $11 / 08$ & $10 / 09$ & $15 / 09$ & $22 / 09$ \\
\hline Sólidos totais & 1430,57 & 1435,80 & * & 1431,49 \\
\hline $\begin{array}{l}\text { Sólidos totais } \\
\text { dissolvidos }\end{array}$ & 1779,10 & 1972,78 & 1973,28 & * \\
\hline \multicolumn{5}{|c|}{ Barragem Eng ${ }^{\circ}$ Armando Ribeiro Gonçalves } \\
\hline Parâmetro & $11 / 08$ & $10 / 09$ & $15 / 09$ & $22 / 09$ \\
\hline Sólidos totais & 1434,96 & 1378,57 & 1337,9 & 1378,70 \\
\hline $\begin{array}{l}\text { Sólidos totais } \\
\text { dissolvidos }\end{array}$ & 1377,83 & 2087,10 & 2052,74 & $*$ \\
\hline \multicolumn{5}{|c|}{ Açude público de Pataxó } \\
\hline Parâmetro & $11 / 08$ & $10 / 09$ & $15 / 09$ & $22 / 09$ \\
\hline Sólidos totais & 1357,40 & 1436,01 & * & 1435,83 \\
\hline \begin{tabular}{|l|} 
Sólidos \\
dissolvidos
\end{tabular} & * & 1779,05 & 1780,40 & * \\
\hline
\end{tabular}

*Os valos que não consta na tabela são os quais não foram analisados nestes determinados dias.

\section{CONCLUSÃO}

Pode-se concluir que, os parâmetros físicos avaliados para águas do vale do Açu, apresenta-se em desconformidade com a resolução 357/2005 do CONAMA. Tanto para sólidos dissolvidos, e dissolvidos totais quanto que para sólidos em suspensão. Isso se 
deve as atividades antropogênicas causadas pelo homem em toda a extensão do reservatório da barragem A. RG. no Rio Açu, e açude pataxó, a correlação entre as análises ficam claras, pois os fatores que defrontam os níveis de potabilidade são os mesmos para as quatro análises. Para tanto é preciso um conjunto de avaliações químicas e microbiológicas mais aprofundadas, que não compunham nesse trabalho, para determinar se a água está ou não própria para consumo.

Analysis of Physical Parameters: Total Solids, Sediments, Total Dissolved Solids and Suspended Solids in the Açu Valley Water

Abstract: It is known that the current drought situation in the Northeast already prevails just over four years. And in the state of Rio Grande do Norte the situation is not different from the others. Currently the largest reservoir that is positioned in one of the important water reserves RN operating at this very low at full capacity about $75 \%$ less, or $25.5 \%$ of the total, the Armando Ribeiro Gonçalves Dam besides supplying over 30 towns, also feeds large projects of multinational companies that have settled in the region for the production of fruit, generating jobs and income populations Açu valley. In addition, it is noteworthy that it is with the dam waters, the Piranhas Acu River is perpetuated bathing several cities to its mouth that goes to the North coast, in Salineira city limits Macau. Por several factors to water becomes for everyone living things, a precious commodity, if not the most important to the survival of all but the human being without measuring consequences ends up degrading what nature offers us. According to the UN about $80 \%$ of the world population lives in areas with high levels of threat to water security. The most serious threats affecting 3.4 billion people, mostly in developing countries. In the case of Brazil despite the large amount of water found in Amazonian rivers, nothing can be done because the country consists of a wide variety of biomes and habitats each with diferenciadas.A From these peculiarities, the considerations Potiguares Water program developed in four Camper IFRN, brings the following proposition to monitor water quality in the surrounding areas of each institute, in addition to awareness of rational use of water. For it lives up to the regiments of Resolution 357/2005 of CONAMA (National Environment Council), analyzing about 24 physical and chemical parameters. So this proposed study is objective, analyze the physical parameters: Total Solids, total dissolved solids Sedimentable solids and suspended solids. And analyze the results by comparing their correlations in the waters of the dam Armando Ribeiro Gonçalves, Açu River and Dam of Pataxó.

Keywords: Potiguares Waters, Valley Açu. 


\section{REFERÊNCIAS BI BLI OGRÁFI CAS}

BRASIL. Ministério do Meio Ambiente. CONAMA. Resolução no 357, de 17 de março de 2005. Dispõe sobre a classificação dos corpos de água. Diário Oficial da República Federativa do Brasil, Poder Executivo, Brasília DF 18 de março, 2005.

SILVA,J.S; SILVA,F.S.B. Considerações sobre agricultura irrigada no vale do Açu e os impactos sobre o mundo do trabalho. Disponível em $<$ http://periodicos.ufpb.br/ojs2/index.php/abet/article/viewFile/15629/8929> acesso em 26 set. 2015.

LEI DAS ÁGUAS DO BRASIL, Disponível em $<$ http://www.planalto.gov.br/ccivil_03/LEIS/L9433.htm> Acesso em 27 set.2015.

SILVA,S.M; THOMAZ, M.R.P; ANDRADE, E.T; HOLMES; E.M. levantamento ambiental do rio piranhas Açu atividades poluidoras ou potencialmente poluidoras, Disponível em $<$ http://www.aesa.pb.gov.br/comites/piranhasacu/igarn/Relatorio_2007 \%20Final_3.p df> acesso em 27 set.2015.

O USO DE UM BEM COLETIVO PARA FINS PRIVADOS, instituto sócio ambiental. Disponível em $<$ http://www. socioambiental.org/inst/camp/Ribeira/energia > acesso em 27 set. 2015. 